Journal of Management and Bussines (JOMB)

Volume 2, Nomor 1, Juni 2020

p-ISSN : 2656-8918

e-ISSN:2684-8317

DOI : https://doi.org/10.31539/jomb.v2i1.1278

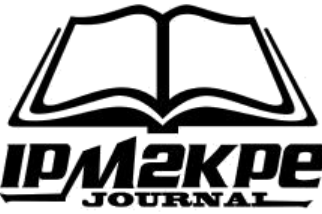

\title{
PENGARUH HARGA KAMAR DAN FASILITAS TERHADAP KEPUTUSAN MENGINAP PADA HOTEL SIMPANG BARU LAHAT
}

\author{
Mujari \\ Sekolah Tinggi Ilmu Ekonomi Serelo Lahat \\ Mujari262729@gmail.com
}

\begin{abstract}
ABSTRAK
Penelitian ini bertujuan untuk mengetahui pengaruh harga kamar terhadap keputusan menginap pada Hotel Simpang Baru Lahat, pengaruh fasilitas terhadap keputusan menginap pada Hotel Simpang Baru Lahat, serta pengaruh harga kamar dan fasilitas terhadap keputusan menginap pada Hotel Simpang Baru Lahat. Hasil Penelitian menunjukan harga kamar dan fasilitas menunjukkan nilai $\mathrm{F}$ hitung $>\mathrm{F}$ tabel $(96,548>$ $5,59)$ dan nilai signifikansi $(0,000<0,05)$. Serta harga kamar, dengan nilai $t$ hitung $>\mathrm{t}$ tabel $(10,626>1,996)$. Untuk variabel fasilitas dengan nilai $t$ hitung $>\mathrm{t}$ tabel $(10,626$ $>1,996)$. Simpulan, harga kamar, pengaruh fasilitas, serta harga kamar dan fasilitas berpengaruh positif dan signifikan dengan keputusan menginap.
\end{abstract}

Kata Kunci: Fasilitas, Harga Kamar, Keputusan Menginap

\section{ABSTRACT}

This study aims to determine the effect of room prices on the decision to stay at the Hotel Simpang Baru Lahat, the influence offacilities on the decision to stay at the Hotel Simpang Baru Lahat, and the influence of room prices and facilities on the decision to stay at the Hotel Simpang Baru Lahat. The results showed the price of rooms and facilities showed a calculated $F$ value $>F$ table (96.548> 5.59) and a significance value $(0.000<0.05)$. As well as the price of the room, with the value of $t$ count $>t$ table (10.626> 1.996). For facility variables with $t$ count> $t$ table (10.626> 1.996). Conclusions, room rates, the effect of facilities, and the price of rooms and facilities have a positive and significant effect on the decision to stay.

Keywords: Facilities, Room Rates, Stay Decisions

\section{PENDAHULUAN}

Di era pembangunan yang semakin berkembang, pertumbuhan ekonomi dan industri telah banyak mengalami kemajuan. Hal ini dapat dilihat dari semakin banyaknya produsen yang terlibat dalam pemenuhan dan keinginan konsumen sehingga tujuan utama perusahaan harus dapat memberikan kepada pelanggan barang atau jasa yang mempunyai nilai tinggi dengan mutu lebih baik, harga lebih murah, sailitas yang memadai dan pelayanan yang lebih baik dari pada pesaingnya (Kotler, 2012). 
Dalam dunia bisnis apabila suatu perusahaan tidak dapat menyusun strategi pemasaran dengan tepat, maka akan mengalami kekalahan dalam bersaing. Dimana strategi bisnis dan strategi pemasaran merupakan salah satu kegiatan pokok yang dapat dilakukan oleh para pengusaha untuk mempertahankan kelangsungan hidupnya, untuk berkembang dan untuk memperoleh keuntungan, salah satu aspek penting dalam pemasaran adalah mendorong calon konsumen untuk menginap intinya perusahaan harus dapat menciptakan cutomer value yang lebih tinggi dibandingkan dengan pesaing, hal itu dilakukan dalam upaya memberikan kepuasan kepada pelanggan (Sarwoto, 2011).

Banyak penginapan modern yang bermunculan saat ini, yang salah satunya adalah Hotel Simpang Baru yang bertempat di Lahat, yang senantiasa ingin memenuhi keinginan dan kebutuhan konsumennya, misalnya kamar VIP yang dilengkapi dengan penghangat ruangan, serta beberapa kamar yang mengahadap ke pemandangan alam serta kebersihan, kelancaran air, kenyaman, harga dan kualitas. Pelayanan yang baik terhadap konsumen dan memuaskan merupakan misi utama bagi sebuah hotel dimana kepuasan konsumen menjadi sorotan-sorotan utama bagi banyak perusahaan-perusahaan dalam memtuskan strategi untuk memenagkan persaingan.Promosi kualitas jasa yang ditawarkan dengan harga murah didukung dengan fasilitas juga menjadi modal utama untuk menarik kepuasan konsumen dalam menginap.

Konsumen dalam menginap juga mempertimbangkan dan memilih lokasi yang akan dikunjungi. Lokasi yang strategi apalagi lebih dekat dengan area wisata yang akan dikunjungi lebih menguntungkan karena selain pemandangan indah, jika akan ke area wisata lebih dekat yang secara tidak langsung akan mempengaruhi konsumen dalam menginap (Basu, 2011).

Sementara itu pelayanan disini adalah segala macam bentuk pelayanan yang diberikan oleh pihak hotel selama tamu atau konsumen tersebut berada dihotel, meliputi pelayanan yang diberikan oleh receptionist, bell boy, room servive, security, cleaning, service, dan lain-lain. Alasannya mengapa penulis memilih harga dan pelayanan sebagai variabel bebas adalah karena penulis ingin melihat seberapa jauh harga dapat berpengaruh terhadap keputusan konsumen untuk menginap di hotel, baik sebelum menginap maupun setelah menginap, juga jauh pelayanan yang diberikan oleh pihak hotel akan berpengaruh terhadap keputusan konsumen dalam menginap di hotel. 
Dari hasil kuisioner yang disebar banyak konsumen yang memilih harga berjumlah 5 orang, yang memilih lokasi berjumlah 3 orang, yang memilih promosi berjumlah 2 orang dan yang meilih fasilitas berjumlah 4 orang dari jumlah keseluruhan adalah 14 orang. Maka dari penelitian pendahuluan tersebut saya mengambil harga sebagai X1 dan fasilitas X2.

\section{KAJIAN TEORI}

\section{Pengertian Harga}

Harga adalah sejumlah uang yang bersedia dibayarkan seorang konsumen untuk mendapatkan barang atau jasa tertentu. Hal ini tercipta apabila demand atas suatu barang dan tersedia supply bagi barang tersebut. Semakin tinggi demand yang terjadi, harga akan bertambah, terutama apabila supply barang yang diinginkan tidak bias memenuhi demand tersebut. Sebagai contoh, seseorang yang memiliki kesukaan travelling akan bersedia mengorbankan waktu, tenaga, dan uang untuk bisa bepergian ke suatu negara. Dalam hal ini, ia bersedia mengeluarkan banyak uang untuk melakukan konsumsi berbagai barang maupun jasa di negara yang ia kunjungi sehingga dari demand tersebut muncul supply dari perusahaan-perusahaan tour \& travel ataupun perusahaan lain terkait seperti hotel ataupun restoran (Annishia, Prastiyo, 2019).

Dalam Lupiyoadi (2011) strategi penentuan harga (pricing) sangat signifikan dalam pemberian value kepada konsumen dan mempengaruhi image produk, serta keputusan konsumen untuk membeli. Harga juga berhubungan dengan pendapatan dan turut mempengaruhi supply atau markering channels. Akan tetapi, yang paling penting adalah keputusan dalam harga harus konsisten dengan strategi pemasaran secara keseluruhan.

Sedangkan Tjiptono (2014) menyatakan bahwa harga juga dapat diartikan sebagai jumlah uang (satuan moneter) dan atau aspek lain (nonmoneter) yang mengandung utilitas/kegunaan tertentu yang diperlukan untuk mendapatkan suatu barang atau jasa. Harga sebuah produk atau jasa merupakan faktor penentu dalam permintaan pasar. Harga merupakan hal yang sangat penting yang diperhatikan oleh konsumen dalam membeli produk atau jasa. Jika konsumen merasa cocok dengan harga yang ditawarkan, maka mereka akan cenderung melakukan pembelian ulang untuk produk yang sama (Annisa, Prastiyo, 2019). 
Menurut Fure (2013) indikator yang digunakan untuk mengukur harga antara lain: Harga yang sesuai dengan manfaat, Persepsi harga dan manfaat, Persaingan harga dan kesesuaian harga dengan kualitasnya

\section{Dimensi Strategi Harga}

Menurut Tjiptono \& Chandra (2012) mengatakan bahwa harga merupakan salah satu elemen bauran pemasaran yang membutuhkan pertimbangan cermat. Ini dikarenakan adanya sejumlah adanya sejumlah dimensi strategik harga dalam hal:

Harga merupakan pernyataan nilai dari suatu produk (a statement of value). Nilai adalah rasio atau perbandingan antara persepsi terhadap manfaat (perceived benefit) dengan biaya-biaya yang dikeluarkan untuk mendapatkan produk.

Harga merupakan aspek yang tampak jelas (visible) bagi para pembeli. Bagi konsumen yang tidak terlalu paham halhal teknis pada pembelian produk otomotif dan elektronik, kerap harga menjadi satu-satunya faktor yang bisa mereka mengerti. Tidak jarang pula harga dijadikan semacam indikator kualitas.

Harga adalah determinan utama permintaan. Berdasarkan hukum permintaan (the law of demand), besar kecilnya harga mempengaruhi kuantitas produk yang dibeli konsumen.

Harga berkaitan langsung dengan pendapatan dan laba. Harga adalah satusatunya unsur bauran pemasaran yang mendatangkan pemasukan bagi perusahaan yang pada gilirannya berpengaruh pada besar kecilnya laba dan pangsa pasar yang diperoleh. Harga bersifat fleksible, artinya bisa disesuaikan dengan cepat.

Harga mempengaruhi citra dan strategi positioning. Dalam pemasaran produk prestisius yang mengutamakan citra kualitas dan eksklusivitas, harga menjadi unsur penting. Konsumen cenderung mengasosiasikan harga dengan tingkat kualitas produk.

Harga merupakan masalah nomor 1 yang dihadapi para manajer. Setidaknya ini ditunjukkan oleh adanya empat level konflik potensial menyangkut aspek harga, yaitu: konflik internal perusahaan, konflik dalam saluran distribusi, konflik dengan pesaing dan konflik tentang instansi pemerintahan dan kebijakan publik. 


\section{Definisi Fasilitas}

Fasilitas adalah sarana yang disediakan oleh hotel, merupakan faktor yang menentukan pilihan orang untuk tinggal atau menyewa di suatu hotel tertentu (Keputusan Menparpostel KM 37/PW. 340.MPRT-86). Menurut Agus Sulastiyono (2011) fasilitas adalah penyedian perlengkapan-perlengkapan fisik untuk memberikan kemudahan kepada para tamu dalam melaksanakan berbagai kegiatan sehingga kebutuhan-kebutuhan tamu dapat terpenuhi selama tinggal di hotel. Tjiptono (2014) faktor-faktor yang berpengaruh signifikan terhadap keputusan desain fasilitas jasa meliputi: (1) Sifat dan tujuan organisasi (2) Ketersedian tanah dan kebutuhan akan ruang/tempat (3) Fleksibel, fleksibelitas desain sangat dibutuhkan apabila volume permintaan sering berfluktuasi dan jika spesifikasi jasa cepat berkembang sehingga resiko keuangan relative besar, (4) Faktor Estetika, faslitas jasa yang tertata rapi, menarik, dan estetis akan dapat meningkatkan sikap positif pelanggan terhadap suatu jasa, (5) Masyarakat dan lingkungan sekitar fasilitas jasa memainkan peranan penting dan berpengaruh besar terhadap perusahaan.

\section{Dimensi Fasilitas}

Menurut Wahyuningrum (2004) dimensi fasilitas dibedakan menjadi 2 bagian yaitu:

Fasilitas fisik adalah segala sesuatu yang berupa benda atau yang dapat dibedakan, yang mempunyai peran dapat memudahkan dan melancarkan suatu usaha.

Fasilitas uang adalah segala sesuatu yang dapat memberi kemudahan suatu kegiatan sebagai akibat dari "nilai uang”.

\section{Definisi Keputusan Menginap}

Kegiatan pemasaran yang dilakukan oleh sebuah perusahaan bertujuan untuk memuaskan kebutuhan (needs) dan keinginan pelanggannya (wants) dalam hal ini yaitu tamu hotel. Tamu hotel mempunyai arti penting bagi perusahaan akomodasi perhotelan yaitu sebagai pengguna produk dan jasa yang ditawarkan oleh perusahaan akomodasi tersebut. Keputusan menginap dalam penelitian ini mengadopsi dari teori keputusan pembelian karena keduanya mempunyai karakteristik yang sama yang 
artinya yang datang ke hotel pasti akan melakukan aktivitas dalam kegiatan pembelian jasa.

Keputusan pembelian menurut Buchari Alma (2011) adalah suatu keputusan konsumen yang dipengaruhi oleh ekonomi keuangan, teknologi, politik, budaya, produk, harga, lokasi, promosi, physical evidence, people dan process, sehingga membentuk suatu sikap pada konsumen untuk mengolah segala informasi dan mengambil kesimpulan berupa tanggapan yang muncul produk apa yang akan dibeli. Berdasarkan pengertian yang telah diungkapkan di atas, maka adanya kesamaan dari keputusan pembelian yang merupakan perilaku para pelanggan yang selalu memutuskan lebih dari satu alternatif dalam menentukan pilihannya untuk mendapatkan produk atau jasa yang diinginkannya. Perilaku konsumen merupakan suatu tindakan yang dilakukan oleh individu, kelompok atau organisasi yang berhubungkan dengan proses pengambilan keputusan.

\section{METODE PENELITIAN}

\section{Desain Penelitian}

Dalam penelitian ini peneliti menggunakan jenis penelitian deskriptif dengan pendekatan kuantitatif. Dalam penelitian ini penulis menganalisa masalah yang ada pada saat sekarang dan membuat gambaran secara sistematis terhadap objek penelitian, maka penelitian ini adalah penelitian deskriptif.

\section{Populasi dan Sampel}

Adapun populasi dalam penelitian ini pelanggan hotel simpang baru Lahat. Sampel yang digunakan dengan metode acidental sampling dan didapat 72 responden.

\section{Sumber Data}

Sumber data pada penelitian ini menggunakan data primer dan data sekunder. Data primer diperoleh langsung dari tempat penelitian. Sedangkan data sekunder adalah data yang dikutif dari sumber lain. Seperti buku-buku, surat kabar, majalah, dan informasi yang berhubungan dengan masalah yang sedang diteliti serta data yang diperoleh langsung dari tempat penelitian. 


\section{Metode Analisis Data}

\section{Uji Asumsi Klasik}

\section{Uji Autokorelasi}

Uji asumsi autokorelasi didefinisikan sebagai hubungan yang terjadi diantara variabel - variabel bebas itu sendiri. Pengujian ada atau tidaknya autokorelasi dalam model regresi dengan menggunakan uji statistik $d$ dari Durbin-Watson (DW). Membandingkan nilai DW yang dihitung dengan nilai kritis dan statistik $d$ adalah cara untuk mengetahui terjadinya autokorelasi. Namun demikian secara umum, dapat diambil patokan sebagai berikut :

Angka D - W 1,54 $<\mathrm{d}<2,46$ artinya tidak ada autokorelsi

Angka D - W 1,10 < d $<2,90$ artinya ada autokorelsi

Angka D - W 1,10 < d $<1,54$ artinya tidak ada keputusan

Angka D - W 2,46 < d $<2,90$ artinya tidak ada keputusan.

\section{Analisis Statistik Infrensial}

\section{Analisis Regresi Berganda}

Analisis Regresi Linier Berganda dengan persamaan:

$$
\mathrm{Y}=\mathrm{a}+\mathrm{b}_{1} \mathrm{X}_{1}+\mathrm{b}_{2} \mathrm{X}_{2}+\mathrm{e}
$$

Dimana :

$$
\begin{array}{ll}
\mathrm{Y} & =\text { Keputusan Menginap } \\
\mathrm{a} & =\text { Konstanta } \\
\mathrm{X} 1 & =\text { Harga } \\
\mathrm{X} 2 & =\text { Fasilitas } \\
\mathrm{b} 1, \mathrm{~b} 2 & =\text { Koefesien Regresi } \\
\mathrm{e} & =\text { error term (kesalahan) }
\end{array}
$$

\begin{tabular}{|c|c|c|}
\hline No & Variabel & Koefisien \\
\hline 1 & Konstanta & 4,495 \\
\hline 2 & Harga Kamar & 0,798 \\
\hline 3 & Fasilitas & 0,391 \\
\hline
\end{tabular}

\section{HASIL PENELITIAN}

\section{Regresi Linier Berganda}

Tabel 1 Hasil Analisis Regresi Linier Berganda Hipotesis 1, 2 dan 3 
$\mathrm{Y}=4,495+0,798 \mathrm{X}_{1}+0,391 \mathrm{X}_{2}$

Persamaan regresi di atas dapat dijelaskan sebagai berikut :

Konstanta sebesar 4,495 artinya jika Harga Kamar $\left(\mathrm{X}_{1}\right)$ dan Fasilitas $\left(\mathrm{X}_{2}\right)$ adalah 0, maka Keputusan Menginap (Y) nilainya adalah 4,495. Koefisien regresi variabel Harga Kamar $\left(\mathrm{X}_{1}\right)$ sebesar 00,798, artinya jika Harga Kamar mengalami kenaikan 1\%, maka Keputusan Menginap (Y) akan mengalami peningkatan sebesar 0,798. Koefisien regresi variabel Fasilitas $\left(\mathrm{X}_{2}\right)$ sebesar 0,391, artinya jika Fasilitas mengalami kenaikan 1\% maka Keputusan Menginap (Y) akan mengalami peningkatan sebesar 0,391.

\section{Koefisien Determinasi}

Hasil analisis determinasi diperoleh angka $\mathrm{R}^{2}(R$ Square) sebesar 0,731 atau $(73,1 \%)$. Hal ini menunjukkan bahwa persentase sumbangan pengaruh variabel independen (Harga Kamar dan Fasilitas) terhadap variabel dependen (Keputusan Menginap) sebesar $73,1 \%$ atau variasi variabel independen yang digunakan dalam model (Harga Kamar dan Fasilitas) mampu menjelaskan 73,1\% variabel dependen (Keputusan Menginap), sedangkan sisanya sebesar 26,9\% dipengaruhi atau dijelaskan oleh variabel lain yang tidak dimasukkan dalam model penelitian ini.

Tabel 2 Hasil Analisis Korelasi Ganda (R) dan Korelasi Determinan (R2)

Model Summary

\begin{tabular}{lcccc}
\hline Model & $\mathrm{R}$ & $\mathrm{R}$ Square & Adjusted R Square & Std. Error of the Estimate \\
\hline 1 & $.855^{\mathrm{a}}$ & .731 & .724 & 2.711 \\
\hline a. Predictors: (Constant), X2, X1 & & \\
\hline \multicolumn{4}{l}{ Sumber : data primer diolah (lampiran 8 halaman 17 tabel model summary) }
\end{tabular}

\section{Uji Simultan (Uji F)}

Tabel 3Hasil Uji F Hipotesis Pertama ANOVAb

\begin{tabular}{lcccccc}
\hline Model & Sum of Squares & Df & Mean Square & F & Sig. \\
\hline 1 & Regression & 1418.972 & 2 & 709.486 & 96.548 & $.000^{\text {a }}$ \\
& Residual & 521.744 & 71 & 7.349 & & \\
\multicolumn{1}{l}{ Total } & 1940.716 & 73 & & \\
\hline
\end{tabular}




\section{Level of significant $a=5 \%$}

$$
\begin{aligned}
& \text { df } 1=3-1=2 \\
& \text { df } 2=74-2-1=71 \\
& \text { df }=5,59
\end{aligned}
$$

\section{Kesimpulan}

Pada tabel 3 nilai $\mathrm{F}$ hitung adalah sebesar 96,548, sedangkan nilai $\mathrm{F}$ tabelnya adalah sebesar 5,59 (df $1=3-1=2$ dan df $2=74-2-1=71$ ). Selain itu, nilai signifikansinya adalah sebesar 0,000 lebih kecil daripada taraf signifikansi $(\alpha) 0,05$. Karena nilai $\mathrm{F}$ hitung $>\mathrm{F}$ tabel $(96,548>5,59)$ dan nilai signifikansi lebih kecil daripada taraf signifikansi $(\alpha) 0,05(0,000<0,05)$, maka hipotesis ketiga diterima, artinya Harga Kamar dan Fasilitas secara simultan berpengaruh positif dan signifikan terhadap Keputusan Menginap.

\section{Uji Parsial (Uji t)}

\section{Uji t Harga Kamar $\left(\mathbf{X}_{1}\right)$ dengan Keputusan Menginap (Y)}

Tabel 4 Hasil Uji T Hipotesis Kedua Coefficientsa

\begin{tabular}{lcccccr}
\hline & \multicolumn{2}{c}{ Unstandardized Coefficients } & Standardized Coefficients & & \\
\cline { 2 - 4 } Model & $\mathrm{B}$ & Std. Error & Beta & $\mathrm{t}$ & Sig. \\
\hline 1 & (Constant) & 4.495 & .860 & & 1.572 & .021 \\
& .798 & .075 & .799 & 10.626 & .000 \\
$\mathrm{X} 1$ & .391 & .075 & .491 & 3.813 & .002 \\
$\mathrm{X} 2$ & & & & &
\end{tabular}

\section{Level of significant $a=5 \%$}

$$
\begin{array}{ll}
\text { Df }(n-2-1) & =74-2-1=71 \\
\mathrm{t} \text { tabel } & =\mathrm{t} 0,05 / 2: 71 \\
\mathrm{t} \text { tabel } & =\mathrm{t} 0,025: 71 \\
\mathrm{t} \text { tabel } & =1,996
\end{array}
$$

\section{Kesimpulan}

Pada tabel 4 nilai t hitung untuk variabel Harga Kamar adalah sebesar 10,626, sedangkan nilai t tabelnya adalah sebesar 1,996. Selain itu, nilai signifikansinya adalah sebesar 0,000 lebih kecil daripada taraf signifikansi $(\alpha) 0,05$. Karena nilai t hitung $>\mathrm{t}$ 
tabel $(10,626>1,996)$, maka hipotesis pertama diterima, artinya Harga Kamar berpengaruh positif dan signifikan terhadap Keputusan Menginap.

\section{Uji t Fasilitas ( $\left.\mathbf{X}_{2}\right)$ dengan Keputusan Menginap ( $Y$ )}

Tabel 5 Hasil Uji T Hipotesis Ketiga

Coefficientsa

\begin{tabular}{|c|c|c|c|c|c|c|}
\hline \multirow{2}{*}{\multicolumn{2}{|c|}{ Model }} & \multicolumn{2}{|c|}{ Unstandardized Coefficients } & \multirow{2}{*}{$\frac{\text { Standardized Coefficients }}{\text { Beta }}$} & \multirow[b]{2}{*}{$\mathrm{t}$} & \multirow[b]{2}{*}{ Sig. } \\
\hline & & $\mathrm{B}$ & Std. Error & & & \\
\hline 1 & (Constant) & 4.495 & .860 & & 1.572 & .021 \\
\hline & $\mathrm{X} 1$ & .798 & .075 & .799 & 10.626 & .000 \\
\hline & $\mathrm{X} 2$ & .391 & .075 & .491 & 3.813 & .002 \\
\hline
\end{tabular}

\section{Level of significant $a=5 \%$}

$$
\begin{array}{ll}
\operatorname{Df}(\mathrm{n}-2-1) & =74-2-1=71 \\
\mathrm{t} \text { tabel } & =\mathrm{t} 0,05 / 2: 71 \\
\mathrm{t} \text { tabel } & =\mathrm{t} 0,025: 71 \\
\mathrm{t} \text { tabel } & =1,996
\end{array}
$$

\section{Kesimpulan}

Pada tabel 5 nilai t hitung Pada tabel 4.14 nilai t hitung untuk variabel Fasilitas adalah sebesar 10,626, sedangkan nilai t tabelnya adalah sebesar 1,996. Selain itu, nilai signifikansinya adalah sebesar 0,002 lebih kecil daripada taraf signifikansi $(\alpha) 0,05$. Karena nilai $\mathrm{t}$ hitung $>\mathrm{t}$ tabel $(10,626>1,996)$, maka hipotesis pertama diterima, artinya Fasilitas berpengaruh positif dan signifikan terhadap Keputusan Menginap.

\section{PEMBAHASAN}

Dalam dunia bisnis apabila suatu perusahaan tidak dapat menyusun strategi pemasaran dengan tepat, maka akan mengalami kekalahan dalam bersaing. Dimana strategi bisnis dan strategi pemasaran merupakan salah satu kegiatan pokok yang dapat dilakukan oleh para pengusaha untuk mempertahankan kelangsungan hidupnya, untuk berkembang dan untuk memperoleh keuntungan, salah satu aspek penting dalam pemasaran adalah mendorong calon konsumen untuk menginap intinya perusahaan harus dapat menciptakan cutomer value yang lebih tinggi dibandingkan dengan pesaing, 
hal itu dilakukan dalam upaya memberikan kepuasan kepada pelanggan (Sarwoto, 2011).

Banyak penginapan modern yang bermunculan saat ini, yang salah satunya adalah Hotel Simpang Baru yang bertempat di Lahat, yang senantiasa ingin memenuhi keinginan dan kebutuhan konsumennya, misalnya kamar VIP yang dilengkapi dengan penghangat ruangan, serta beberapa kamar yang mengahadap ke pemandangan alam serta kebersihan, kelancaran air, kenyaman, harga dan kualitas. Pelayanan yang baik terhadap konsumen dan memuaskan merupakan misi utama bagi sebuah hotel dimana kepuasan konsumen menjadi sorotan-sorotan utama bagi banyak perusahaan-perusahaan dalam memtuskan strategi untuk memenagkan persaingan.Promosi kualitas jasa yang ditawarkan dengan harga murah didukung dengan fasilitas juga menjadi modal utama untuk menarik kepuasan konsumen dalam menginap.

Konsumen dalam menginap juga mempertimbangkan dan memilih lokasi yang akan dikunjungi. Lokasi yang strategi apalagi lebih dekat dengan area wisata yang akan dikunjungi lebih menguntungkan karena selain pemandangan indah, jika akan ke area wisata lebih dekat yang secara tidak langsung akan mempengaruhi konsumen dalam menginap (Basu, 2011).

Sementara itu pelayanan disini adalah segala macam bentuk pelayanan yang diberikan oleh pihak hotel selama tamu atau konsumen tersebut berada dihotel, meliputi pelayanan yang diberikan oleh receptionist, bell boy, room servive, security, cleaning, service, dan lain-lain. Alasannya mengapa penulis memilih harga dan pelayanan sebagai variabel bebas adalah karena penulis ingin melihat seberapa jauh harga dapat berpengaruh terhadap keputusan konsumen untuk menginap di hotel, baik sebelum menginap maupun setelah menginap, juga jauh pelayanan yang diberikan oleh pihak hotel akan berpengaruh terhadap keputusan konsumen dalam menginap di hotel.

\section{SIMPULAN}

1. Berdasarkan persamaan regresi linier berganda $Y=4,495+0,798 X_{1}+0,391 X_{2}$. Persamaan regresi di atas dapat dijelaskan sebagai berikut :

a) Jika Harga Kamar mengalami kenaikan 1\%, maka Keputusan Menginap (Y) akan mengalami peningkatan sebesar 0,798. 
b) Jika Fasilitas mengalami kenaikan 1\% maka Keputusan Menginap (Y) akan mengalami peningkatan sebesar 0,391 .

2. Pengaruh variabel independen (Harga Kamar dan Fasilitas) terhadap variabel dependen (Keputusan Menginap) sebesar 73,1\% atau variasi variabel independen yang digunakan dalam model (Harga Kamar dan Fasilitas) mampu menjelaskan 73,1\% variabel dependen (Keputusan Menginap), sedangkan sisanya sebesar 26,9\% dipengaruhi atau dijelaskan oleh variabel lain yang tidak dimasukkan dalam model penelitian ini.

3. Harga Kamar dan Fasilitas secara simultan berpengaruh positif dan signifikan terhadap Keputusan Menginap.

4. Nilai Variabel Independen $\left(\mathrm{X}_{1}\right.$ dan $\left.\mathrm{X}_{2}\right)$

a) Harga Kamar berpengaruh positif dan signifikan terhadap Keputusan Menginap.

b) Fasilitas berpengaruh positif dan signifikan terhadap Keputusan Menginap.

\section{DAFTAR PUSTAKA}

Annishia, F. B., \& Prastiyo, E. (2019). Pengaruh Harga dan Fasilitas terhadap Keputusan Menginap Tamu di Hotel Best Western Premier the Hive Jakarta. Jurnal Hospitality dan Pariwisata, 4(1), 19-28. http://journal.ubm.ac.id/

Basu, S. (2011). Manajemen Pemasaran. Yogyakarta: PT BPE

Buchari, A. (2011). Manajemen Pemasaran dan Pemasaran Jasa. Cetakan Kesembelian. Bandung: Alfabeth

Fure, H. (2013). Lokasi, Keberagaman Produk, Harga dan Kualitas Pelayanan pengaruhnya terhadap Minat Beli pada Pasar Tradisional Bersehati Calaca. Universitas Sam Ratulangi, Manado

Kotler, P. (2012). Manajemen Pemasaran, Suatu Pendekatan Analisis, BFFE. Yogyakarta

Lupiyoadi, R. (2011).Manajemen Pemasaran Jasa Teori dan Praktik. Jakarta: Penerbit Salemba Empat

Sarwoto, S. (2011). Dasar-dasar Organisasi dan Management. Jakarta: Ghalia Indonesia

Sulastiyono, A. (2011). Manajemen Penyelanggaraan Hotel. Bandung: Alfabeta

Tjiptono, F. (2014). Pemasaran Jasa. Jakarta: Gramedia Cawang

Tjiptono, F., \& Candra, C. (2012). Pemasaran Jasa. CV . Yogyakarta: Andi Offset

Wahyuningrum, W. (2004) Buku Ajar Manajemen Fasilitas Pendidikan.Yogyakarta:

FIP UNY. (Online) http// staff UNY.ac.id/Bab manajemen fasilitaspendidikan.html 